\title{
Structural Modeling on the Relationship between Basic Psychological Needs, Academic Engagement, and Test Anxiety
}

\author{
Farnaz Mehdipour Maralani ${ }^{1}$, Masoud Gholamali Lavasani ${ }^{1} \&$ Elahe Hejazi ${ }^{1}$ \\ ${ }^{1}$ Faculty of Education and Psychology, University of Tehran, Tehran, Iran \\ Correspondence: Farnaz Mehdipour Maralani, Faculty of Education and Psychology, University of Tehran, \\ Tehran, Iran. Tel: 98-021-6111-7400. E-mail: fmehdipourm@ut.ac.ir
}

Received: March 25, 2016

Accepted: June 30, 2016

Online Published:August 24, 2016

doi:10.5539/jel.v5n4p44

URL: http://dx.doi.org/10.5539/jel.v5n4p44

\begin{abstract}
Some of the key issues in educational psychology are the way of students' engagement at school, controlling anxiety, and academic achievement. In line with that, the purpose of the present study is to determine the relationship between variables that are basic psychological needs, academic engagement, and test anxiety with regard to structural equation modeling. Therefore, the cluster sampling of 289 female students of Hamedan province was carried out in some phases. Also, the participants were supposed to fill some questionnaires on aspects of academic engagement (Reeve \& Tseng, 2011), basic psychological needs (La Guardia, 2000), and Ahwaz inventory test anxiety (2002). The results of structural equation modeling show that exogenous variable of basic psychological needs effects directly positive and significantly on academic engagement; also, effects directly negative and meaningfully on test anxiety. However, the indirect effect on test anxiety because of academic engagement is not significant. The justification is that the relationship between academic engagement and test anxiety is not meaningful. According to findings, basic psychological needs can be highlighted as the most important factor so as to increase academic engagement of students, and decrease their test anxiety.
\end{abstract}

Keywords: basic psychological needs, academic engagement, and test anxiety

\section{Introduction}

One of the main plans in order to optimizing education is that students' academic achievement have to be considered. Therefore, identifying these factors are highly significant (Pourki, 1970; as cited in Koutsoulis \& Campbell, 2001). Also, academic engagement, as a part of human's motivational model that develops during the last recent decades, effects on academic achievement (Connell \& welborn, 1991).

By referring to academic achievement, it is possible to explain that how students may feel and react on school's atmosphere and tasks (Fredericks, Blumenfeld, \& Paris, 2004). In model which is provided by Finn (1989) achievement includes two aspects, that is, "behavioral" and "emotional". Newman et al. ((1992) as cited in Appelton et al., 2006), and Marks (2000) posit three sub-classifications for the term engagement which includes behavioral, cognition, and emotional aspects. On the other hand, Appelton et al. (2006) propose that engagement may include four indices, "educational", "behavioral", "cognitive", and "psychological". Therefore, "educational index" defines as the amount of time spending on covering assignments, receiving any educational credit from individual perspective, and completing homework. Also, "behavioral index" explains the notions of attention, and voluntary participating in class and extra curriculum programs. Finally, "cognition" and "psychological" indices include self-regulation, learning value, personal goals, and automatism; and having sense of belonging and relationship with teachers and of the same age friends, respectively. Reeve and Tseng (2011) beside cognitive, emotional, and behavioral aspects add the other feature which called as agency. Veiga (2016) also conducts some studies on the concepts of engagement at school along with the other four features (cognitive, emotional, behavioral, and agency), that the last among four ones refers to actively interested in, and having self-confidence on learning and acquiring knowledge.

Research shows that there is a relationship between academic engagement with high educational achievement, and lack of academic engagement and low educational achievement (Kelly, 2008). In recent decades, academic engagement attracts a lot of attentions since it can provide a framework which leads into perceiving the cause of educational problems such as dropping out especially in adolescents (Shernoff, 2013). Because adolescent faces wide varieties of challenges like social impacts and individual developments that overshadow his/her 
performance and academic engagement (Libbey, 2004). As a result, academic engagement carries importance in all levels especially in adolescent, also it should be noted that academic engagement of high school student may predict his/her later challenges at university (Shernoff \& Hoogstra, 2001). Furthermore in case of students' engagement with considering their genders, result of the study shows that the relationship between gender differences and educational performance and engagement was observed. That is to say, academic engagement level of female students were significantly higher than male students (Fullarton, 2002). Therefore, in the present study the effect of this variable, significant factors which effect on that and its results on female adolescent students will be taken into consideration.

Ratelle and Duchesne (2014) believe that perception of students toward satisfying their basic needs can predict educational adjustment, spontaneity, engagement, and educational achievement. Basic psychological needs as a motivational factor help individual to actively and academically engage (Talley et al., 2012).

One of the brilliant concepts of engagement is that it can develop one's self-system Model. According to this model, student may need sense of competence, autonomy, and relatedness (Connell, 1990). Competence, as one of the vital factors refers to individual's experience in interaction with social and physical environments. Students who have higher sense of competence, less suffer from anxiety, and can deal with higher levels of challenges which lead to more engagement at school (Harter, 1982).

Moreover, having perception of educational competence influences on academic autonomy, and student's performance result (Fortier, Vallerand, \& Guay, 1995). Autonomy, refers to the degree of freedom that student needs to determine his/her behavior (Skinner, 1995). According to self-determination theory (Deci \& Riyan, 2000), sense of autonomy plays an important role in improvement of individual's performance, because each individual will see him/herself as a responsible one for his/her action. Therefore, there is no control from outside world so that psychological behavior much more increases one's his/her performance and engagement (Kuvaas, 2009). On the other hand, when student can experience warmth, to be loved, and having value in his/her interactions; therefore, need of relatedness will satisfy (Hejazi et al., 1393).

Connell and Wellborn (1991) emphasis the role of relatedness and autonomy in academic engagement. Reeve et al. (2004) in their studies show that if teachers support students' sense of autonomy academic engagement may increase. Hejazi et al. (1393) conducted a study on the relationship between teacher and student, and school engagement which basic psychological needs play as the mediator. Therefore, the direct and indirect relationship of student's perception to have relatedness with teachers and school engagement were examined. The results of the study show that the direct relationship of students' perception to have relatedness with teachers, and school engagement is not significant. However, the indirect relationship of these two variables which is mediated by basic needs is significant.

Also, there is a negative correlation between academic engagement and major educational results like test anxiety. Generally, adolescents experience large variety of anxieties. Although having constructive degree of anxiety may help individual to do the tasks regularly, this kind of anxiety may also cause extreme difficulty for individuals in daily life and education. That one of them is test anxiety which carries emotional or unpleasing feeling. Also, by having test anxiety learning will be difficult, and grades follow a downward trend. Test anxiety as one of the most significant educational problems affects millions of students around the world which decreases educational performance. And most importantly, the reason of students' weakness in education is not disability in learning rather it refers to students whom suffering from a high level of test anxiety (Khosravi \& Bigdeli, 1387).

Individuals who suffer from anxiety evaluate themselves negatively so that distracts their attention while sitting an exam (Gholamali Lavasani, Ezheii, \& Davoudi, 1392). Test anxiety also effects on concentration and memory, as well as decreasing ability to remember learned materials. Hence, the real abilities of students could not be observed (Sarason, 1988). Test anxiety defines two indices of "concern", and "excitement". "concern" meant having cognitive anxiety on the aftermaths of failing (Liebert \& Morris, 1967); and "excitement" causes psychological changes which are the results of automatic innervation (Spielberger \& Vagg, 1995). Therefore, it seems that negative and ineffective thoughts interfere with cognitive process on exam session, and result in diminishing students' performance (Crişan \& Copaci, 2015). Students who suffer from test anxiety have negative evaluation from their performance (Sarason, 1984). Considering Bandura's cognition-social model (1997) students with having anxiety shows low level of his/her competence. Research shows that test anxiety can be predicted by educational self-concept (Iroegbu, 2013). Many previous studies also present that self-concept precede anxiety (Ahmed, Minnaert, Kuyper, \& Werf, 2012). Students with having positive self-concept apply self-regulatory strategies so as to highly involve in education, and as a result experience less anxiety which 
effects on academic performance (González, Rodríguez, Faílde, \& Carrera, 2016). Hence, academic engagement can change both negative thoughts and self-concept as well as lessen prediction of test anxiety.

Raufelder, Hoferichter, Ringeisen, Regner, and Jacke (2015) examined perception of parents' supportive and assertive roles in relationship with test anxiety and academic engagement. Results also showed that academic engagement of female student was caused by mothers, and academic engagement and test anxiety of male student were caused by fathers.

Academic engagement can determine low level of educational achievement, high level of tiresome and lack of students' interest, along with high numbers of quitting education (Fredericks, Blumenfeld, \& Paris, 2004). Therefore, academic engagement is one of the necessary issues which has to be considered so as to improve academic performance. And back to its importance, studying effective factors and variables should be highlighted since by observing the effect of behavioral, cognitive, and emotional variables on students, the prerequisites of students' academic improvement can be provided. The significances of academic engagement in all grades, especially for adolescents, is highly important. As a result, it is crucial to study on academic engagement's predictive variables. In adolescent, attempts for satisfying the basic needs increase (Zimmer-Gembeck \& Collins, 2003).

When the developmental needs of students are met, it is more likely that they pay more attention both to school tasks, and to doing assignments (Hejazi et al., 1393). Based on that, it is possible to predict the basic psychological needs as an academic engagement.

While academic engagement can predict educational achievement (Dotterer \& Lowe, 2011), test anxiety can be shown as a barrier to academic performance (Hembree, 1988).

Test anxiety of students may also because of the effects of different variables, which by identifying and knowing their effects, test anxiety decreases. Hence, in the present study test anxiety will be taken into consideration by noticing to variables of basic psychological needs and academic engagement. According to conducted studies, basic psychological needs have direct impact on academic engagement (Hejazi et al., 1393).

Moreover, Raufelder et al. (2015) findings show the relationship between controlling test anxiety and academic engagement, and parents' supports as mediators. Also in spite of doing numerous research on test anxiety in adolescent, a few study has been done on test anxiety and academic engagement (Raufelder et al., 2015). Researchers attempt to find a relationship between test anxiety and academic engagement, and social context.

Therefore, it is supposed that basic psychological needs have direct impact, and academic engagement as a mediator has indirect effects on decreasing test anxiety. Based on what proposed the purpose of the present study is applying structural equation modeling in test, so that this conceptual model can measure the relationship between variables of basic psychological needs, test anxiety, and academic engagement.

\subsection{Conceptual Model}

Test anxiety is an important endogenous variable, that effect students performance and academic achievements. So, it is necessary to identifying the factors affected on it. One of these factors is basic psychological needs, that is studied as an exogenous variable in this research. The students suffer from test anxiety consider themselves incompetent. There for, they do not have any confidence in their relationship with teachers and classmates. Also, because they do not feel competence, they do not feel autonomous too. So, basic psychological needs affects test anxiety.

According to self-system model, Satisfaction of basic psychological needs will affect on academic engagement, there for, Because of the importance of basic psychological needs, academic engagement and test anxiety, in this study we want to show the relationship between these variables. 


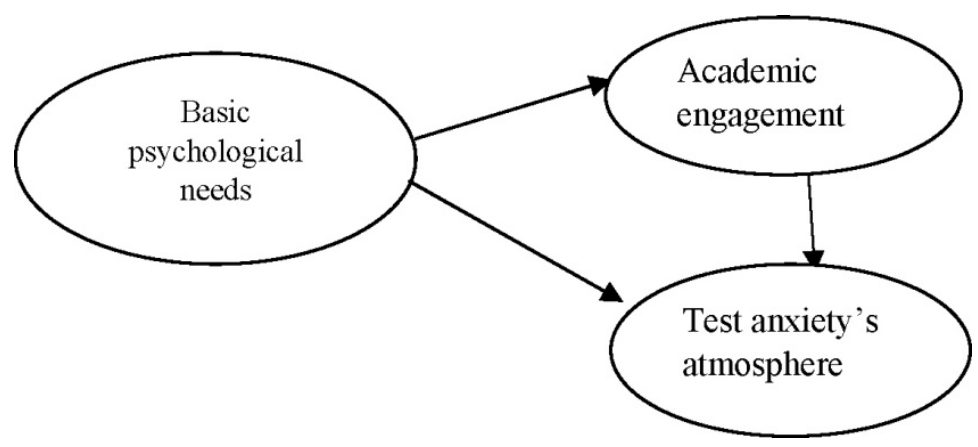

Figure 1. The relationship between basic psychological needs, academic engagement, and test anxiety's atmosphere

\section{Method}

The present study is non-experimental, and its design is correlational based on structural equation modeling.

\subsection{Statistical Population and Sampling}

The statistical population of the study are all math-physics and experimental sciences female students of the second and third grade in Hamedan. A city in Iran, high schools in the 94-95 school year. Multistage cluster sampling has been used; two high schools have been randomly selected from the two districts of Hamedan and 289 math-physics and experimental sciences female students have been studied as samples.

\subsection{Instruments}

Questionnaire on aspects of academic engagement: the present questionnaire aimed to consider four academic engagement features (cognitive, behavioral, emotional, and agency) developed by Reeve and Tseng (2011). It is also composed of 22 questions with 7 point Likert scales (strongly disagree, disagree, somehow disagree, average, somehow agree, agree, and strongly agree. Reeve and Tseng (2011) measure five variables in students' behavioral engagement. And the reliability of which were measured by $0.94 \%$ Chronbach's alpha coefficient. Also, for measuring emotional engagement a self-report scale was used (Skinner et al., 2009; as cited in Reeve \& Tseng, 2011). This scale includes four variables which can report students' emotional state while doing school assignments. Reeve and Tseng (2011) measured the reliability of these four variables by applying $0.78 \%$ Cronbach's alpha coefficient. Also for measuring cognitive engagement the questionnaire of learning strategy (Wolters, 2004 as cited in Reeve \& Tseng, 2011) was used. This scale of measurement derived from two sub-scale features that are evaluation of learning complexity strategies based on developmental aspects (questions 15-18 related to cognitive engagement), and the second subscale refers to evaluation of meta-cognitive and self-regulative features like planning, observing, and improving the task (questions 19-22 related to cognitive engagement). Reeve and Tseng (2011) measured the reliability of these 8 factors with $0.88 \%$ Cronbach's alpha coefficient. They also proposed that since engagement was a new factor, it was not possible to rely on a previously reliable measurement. Therefore, based on observational system (observation of classroom goals), self-report scale, and conceptual framework which was developed previously, five variables for measuring that new scale were developed. Reeve and Tseng (2011) measured the reliability based on $0.82 \%$ Cronbach's alpha coefficient. And based on measured Cronbach alpha coefficient $(\alpha=0.71)$, academic engagement scale is also valid. As for validity of the instrument, confirmatory analysis was used which fitness indices were $(\mathrm{GFI}=0.99, \mathrm{AGFI}=0.97, \mathrm{CFI}=1, \mathrm{RMSEA}=0.04)$.

\subsection{Basic Psychological Needs}

In order to measure this variable the scale of basic psychological needs was applied (La Guardia, 2000). This 21 sub-scales measure 7 sub-scale autonomy, 6 subscales of competence, and 8 relatedness sub-scales. For example, one of the scales of autonomy is "I feel I can have suggestions on how to study and do assignments in the classroom". The other scale refers to need for having relatedness that is "I occasionally feel to have improvement in the classroom". All scales were developed based on a five-point-likert scale, 1: completely wrong to 5: completely right. The reliability efficiency of the scale was 0.83 by using Cronbach's alpha coefficient (Deci \& Riyan, 2001). Moreover for autonomy, competence, and relatedness, the results were $0.60,0.59$, and 0.79 , orderly. Also, confirmatory analysis was used to measure validity that the fitness indices were (GFI $=0.94$, AGFI $=0.91$, CFI $=0.95$, RMSEA $=0.06$ ). 


\subsection{Ahwaz Inventory Test Anxiety}

The present inventory is used statistical analysis to analyze factors which affect measuring test anxiety by Aboulghasemi, Asadi Moghadam, Najarian, and Shekarkan (Aboulghasemi, 2002), which is a 25 paper-pencil tests of self-report.

Participants chose one among four options (never, rarely, sometimes, and often). The preliminary questionnaire of test anxiety includes 93 items which was randomly given to 581 female and male students of Ahwaz third grade of guidance school, and for consistency evaluation Cronbach's alpha coefficient was used. According to endogenous TAI the Cronbach's alpha coefficient for all female and male participants were reported 0.94, 0.95, and 0.92 , respectively. As for reliability of the test anxiety in the present study, Cronbach's alpha coefficient was used, and based on its finding test anxiety carried acceptable reliability $(\alpha=0.93)$ which can be applied for measuring student's test anxiety. Also, confirmatory analysis was used to measure validity of fitness indices (GFI $=0.97$, AGFI $=0.93, \mathrm{CFI}=0.98$, RMSEA $=0.08$ ).

\section{Results}

Before dealing with structural model test, Table 1 depicts the descriptive variables (average, standard deviation, skewedness, and kurtosis) so as to observe good dispersion, and normal distribution of data. Skewedness and kurtosis indices show normality of distributed data. Also, Table 2 presents correlation between research variables. In order to observe the causality between variables, structural equation modeling was applied. In the present research model, variable of basic psychological needs was identified as an exogenous variable, and academic engagement and test anxiety variables were defined as endogenous variables.

Table 1. Descriptive indices of research variables

\begin{tabular}{ccccc}
\hline Variables & Mean & SD & Kurtosis & Skewness \\
\hline $\begin{array}{c}\text { Basic } \\
\text { Psychological } \\
\text { needs }\end{array}$ & 3.43 & 0.54 & -0.05 & -0.03 \\
$\begin{array}{c}\text { Academic } \\
\text { engagement }\end{array}$ & 3.56 & 0.56 & -0.30 & -0.20 \\
\begin{tabular}{c} 
Test. Anxiety \\
\hline
\end{tabular} & 1.21 & 0.77 & -0.64 & 0.25 \\
\hline
\end{tabular}

Table 2. Correlational matrix of research variables

\begin{tabular}{|c|c|c|c|}
\hline Variables & Psychological Needs & Academic Engagement & Test Anxiety \\
\hline Psychological Needs & 1 & & \\
\hline Academic Engagement & $0.51 * *$ & 1 & \\
\hline Test Anxiety & $-0.36 * *$ & $-0.28 * *$ & 1 \\
\hline
\end{tabular}

According to Table 2, the highest level of correlations in variables related to the relationship between academic engagement and basic psychological needs is $(0.51)$, basic psychological needs and test anxiety is $(-0.36)$, and academic engagement and test anxiety is $(-0.28)$, respectively.

Figure 2 shows fitted model of test anxiety prediction along with goodness of fit indices.

Figures are standardized on routes and parameters. According to Figure 2, the direct effect of academic engagement on test anxiety is not meaningful, and all the other routes are significant at 0.01 level. Among the present variables in this model, basic psychological needs $(0.71)$ carries the most direct effect on academic engagement. 


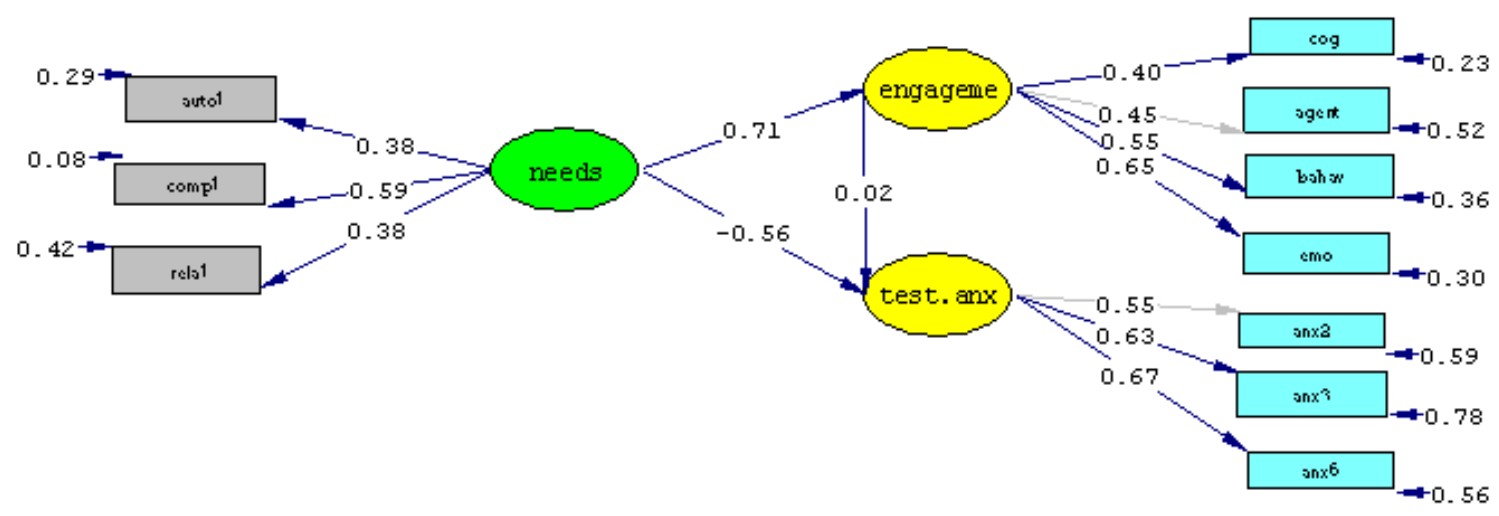

Figure 2. Fitted model of test anxiety prediction

In order to observe fitness of model, the following indices were used. In Goodness of Fit Index (GFI), and Comparative Fit Index (CFI), the outcome of more than 0.9 is acceptable. In adjusted goodness of fit index (AGFI), the outcome of more than 0.9 is acceptable. Also, in Root Mean Square Error of Approximation (RMSHEA), the result of less than 0.8 shows the fitness of model (Houman, 1387). The acceptable ratio of Chi square on degree of freedom $\left(\chi^{2} / \mathrm{df}\right)$ have to be less than 3 (Kline, 2011). Table 3 also depicts goodness of fit indices model in an optimum level.

Table 3. Indices of fitted model

\begin{tabular}{ccccccc}
\hline$\chi^{2}$ & Df & $\chi^{2} / \mathrm{df}$ & CFI & GFI & AGFI & RMSEA \\
\hline 79.20 & 31 & 2.55 & 0.96 & 0.95 & 0.91 & 0.07 \\
\hline
\end{tabular}

Table 4 presents direct, indirect, and whole impact efficiencies, defined variance, and level of significance between variables.

As Table 4 shows, the exogenous variable of basic psychological needs (0.71) plays a direct significant role on academic engagement. Basic psychological needs $(-0.56)$ also effects directly on test anxiety; and indirect effect of basic psychological needs, because academic engagement not carry importance on test anxiety, is not significant, and the effect of academic engagement on test anxiety is not meaningful.

Table 4. Direct, indirect, and whole model standard efficiency, and defined efficiency

\begin{tabular}{|c|c|c|c|c|}
\hline Path & Direct Effect & In Direct effect & Total Effect & $\begin{array}{l}\text { Coefficient of } \\
\text { Determination }\end{array}$ \\
\hline On test anxiety from & & & & 0.29 \\
\hline Psychological needs & $-0.56^{* *}$ & 0.01 & & \\
\hline Academic Engagement & 0.02 & - & $-0.55^{* *}$ & \\
\hline ON Engagement from & & & 0.02 & 0.56 \\
\hline Psychological needs & $0.71 * *$ & - & & \\
\hline
\end{tabular}




\section{Discussions}

the purpose of the present study is applying structural equation modeling in test, so that, this conceptual model can measure the relationship between variables of basic psychological needs, test anxiety, and academic engagement.

Therefore, a conceptual model was chosen, and modeling was used to measure structural equations. Results of the study show that the chosen model fitted with data, and can explain $29 \%$ of test anxiety variance, along with $56 \%$ of academic engagement variance.

The obtained results of structural equation modeling show that basic psychological needs effect directly and significantly, but negatively on test anxiety. The findings are in along with Chirkou and Rayan (Chirkou \& Rayan, 2001; as cited in Siyadat, 1390) that teachers and parents supports may result in having motivated Russian and American high school students with sense of self-determination. Also, Raufelder et al. (2015) believe that parents supportive and assertive role plays meaningful relationship between test anxiety and academic engagement. Also, research shows that basic psychological needs effect positively and significantly on academic engagement. Hejazi et al. (1393) also reported the same result. The indirect effect of basic psychological needs on test anxiety, and direct effect of academic engagement on test anxiety were not significant. Of course, the results are not in align with Raufelder et al. (2015) findings, that is on the relationship between controlling test anxiety and academic engagement with the supportive role of parents on adolescents as a mediator factor. In general, fitted model shows that exogenous variable of basic psychological needs effect directly on academic engagement and test anxiety.

Since adolescents try to satisfy their needs increasingly (Zimmer-Gembeck \& Collins, 2003), creating an atmosphere for them that can be felt sense of autonomy, relatedness, and competence is highly considerable so as to result effectively in improvement and engagement of students at school. When students perceive that attention can be paid on their basic psychological needs, they will do their assignments enthusiastically; hence, test anxiety decreases (Hejazi et al., 1393). Finally, with regard to the importance of basic psychological needs on academic engagement and test anxiety, it is recommended that teachers should be as knowledgeable as possible about basic needs so that be able to distinguish which tasks will be effective to satisfy students basic psychological needs. The results of this study will be applicable for educational planning and administration since adopting appropriate academic policy, academic engagement of students, and decreasing test anxiety can be taken into account in practice.

The present study was conducted on second and third grade high school students majoring in mathematics and natural science. Therefore, it is suggested that the same study carry out among other majors and grades. Also since the direct relationship between academic engagement and test anxiety is not significant, it is better to consider the role of academic engagement on test anxiety with regard to other mediator variables.

\section{References}

Aboulghasemi, A. (2002). Assessment of anxiety and epidemiological efficacy of treatment methods in reducing test anxiety middle school [Dissertation]. Ahwaz: Shahid Chamran University.

Ahmed, W., Minnaert, A., Kuyper, H., \& van der Werf, G. (2012). Reciprocal relationships between math self-concept and math anxiety. Learning and Individual Differences, 22(3), 385-389. http://dx.doi.org/10.1016/j.lindif.2011.12.004

Appelton, J. J., Chestenson, S. L., Kim, D., \& R eschly, A. (2006). Measuring cognitive and psychological engagement: Validation of the student engagement instrument. Journal of School Psychology, 44, 427-445. http://dx.doi.org/10.1016/j.jsp.2006.04.002

Bandura, A. (1997). Self-efficacy: The exercise of control. New York, NY: W H Freeman/TimesBooks/Henry Holt \& Co.

Connell, J. P. (1990). Context, self, and action: A motivational analysis of selfsystem processes across the life-span. In D. Cicchetti, \& M. Beeghly (Eds.), The self in transition: From infancy to childhood (pp. 61-97). Chicago: University of Chicago Press.

Connell, J. P., \& Wellborn, J. G. (1991). Competence, autonomy and relatedness: A motivational analysis of self-system processes. In M. Gunnar, \& L. A. Sroufe (Eds.), Minnesota Symposium on Child Psychology: Self processes and development (Vol. 23, pp. 43-77). Chicago: University of Chicago Press. 
Crişan, C., \& Copaci, I. (2015). The Relationship between Primary School Childrens' Test Anxiety and Academic Performance. Procedia-Social and Behavioral Sciences, 180, 1584-1589. http://dx.doi.org/10.1016/j.sbspro.2015.02.311

Deci, E. L., \& Ryan, R. M. (2000). The "what" and "why" of goal pursuits: Human needs and the

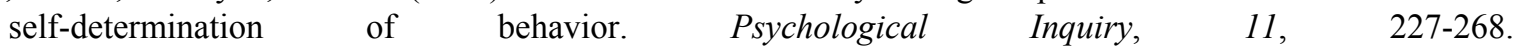
http://dx.doi.org/10.1207/S15327965PLI1104_01

Deci, E. L., Ryan, R. M., Gagne, M., Leone, D. R., Usunov, J., \& Kornazheva, B. P. (2001). Need satisfaction, motivation, and well-being in the work organizations of a former eastern bloc country: A cross-cultural study of self-determination. Society for Personality and Social Psychology, 27, 930-942. http://dx.doi.org/10.1177/0146167201278002

Dotterer, A. M., \& Lowe, K. (2011). Classroom context, school engagement, and academic achievement in early adolescence. Journal of Youth and Adolescence, 40, 1649-1660. http://dx.doi.org/10.1007/s10964-011-9647-5

Gholam Ali Lavasani, M., Ezheii, J., \& Davoudi, M. (1392). The effect of teaching self-regulatory learning strategies on academic engagement skills, and self-regulatory test anxiety. Psychology, 2, 169-181.

González, A., Rodríguez, Y., Faílde, J. M., \& Carrera, M. V. (2016). Anxiety in the statistics class: Structural relations with self-concept, intrinsic value, and engagement in two samples of undergraduates. Learning and Individual Differences, 45, 214-221. http://dx.doi.org/10.1016/j.lindif.2015.12.019

Finn, J. D. (1989). Withdrawing from school. Review of Educational Research, 59, 17-142. http://dx.doi.org/10.3102/00346543059002117

Fortier, M. S., Vallerand, R. J., \& Guay, F. (1995). Academic motivation and school performance: Toward a structural model. Contemporary Educational Psychology, 20, 257-274. http://dx.doi.org/10.1006/ceps.1995.1017

Fredericks, J. A., Blumenfeld, P. C., \& Paris, A. H. (2004). School engagement: Potential of the concept, state of the evidence. Review of Educational Research, 74, 59-109. http://dx.doi.org/10.3102/00346543074001059

Fullarton, S. (2002). Student engagement with school: Individual and school-level influences. Australian Council for educational research.

Harter, S. (1982). The perceived competence scale for children. Child Development, 53, 87-97. http://dx.doi.org/10.2307/1129640

Hejazi, E., Tabatabaii, M., Lavasani, M., \& Moradi, A. (1393). The relationship between teacher and student, and engagement at school: The mediator role of basic psychological needs. Applied Psychological Research Quarterly, 5(1), 19-40.

Hembree, R. (1988). Correlate, causes, and effects of test anxiety. Review of Educational Resaerch, 58, 47-77. http://dx.doi.org/10.3102/00346543058001047

Houman, H. A. (1387). Structural Equation Modeling by Applying Lisrel Software (2nd ed.). Samt Publication, Tehran.

Iroegbu, M. N. (2013). Effect of test anxiety, gender and perceived self-concept on academic performance of Nigerian students. International Journal of Psychology and Counselling, 5(7), 143-146.

Kelly, S. (2008). Race, social class, and student engagement in middle school English classrooms. Social Science Research, 37(2), 434-448. http://dx.doi.org/10.1016/j.ssresearch.2007.08.003

Khosravi, M., \& Bigdeli, E. (1387). The relationship between personality traits and test anxiety in university students. Behavioral Sciences, 2(1), 13-24.

Kline, R. B. (2011). Principles and practice of structural equation modeling (2nd ed.). New York, NY: The Guilford Press.

Koutsoulis, M. K., \& Campbell, J. R. (2001). Family processes affect students motivation and science and math achievement in High School. Structural Equation Modeling, 8(1), 108-127. http://dx.doi.org/10.1207/S15328007SEM0801_6

Kuvaas, B. (2009). A test of hypotheses derived from self-determination theory among public sector employees. Employee Relations, 31(1), 39-56. http://dx.doi.org/10.1108/01425450910916814 
La Guardia, J. G., Ryan, R. M., Couchman, C. E., \& Deci, E. L. (2000). Within-person variation in security of attachment: A selfdetermination theory perspective on attachment, need fulfillment, and well-being. Journal of Personality and Social Psychology, 79, 367-384. http://dx.doi.org/10.1037/0022-3514.79.3.367

Libbey, H. (2004). Measuring student relationship to school: Attachment, bonding, connectedness and $\begin{array}{lllll}\text { engagement. Journal } & \text { 274-283. }\end{array}$ http://dx.doi.org/10.1111/j.1746-1561.2004.tb08284.x

Liebert, R. M., \& Morris, L. W. (1967). Cognitive and Emotional Components of Test Anxiety: A Distinction and some Initial Data. Psychological Reports, 20, 975-978. http://dx.doi.org/10.2466/pr0.1967.20.3.975

Marks, H. M. (2000). Student engagement in situational activity: Patterns in the elementary ,middle, and high school years. American Educational Research Journal, 37(1), 84-153. http://dx.doi.org/10.3102/00028312037001153

Ratelle, C. F., \& Duchesne, S. (2014). Trajectories of psychological need satisfaction from early to late adolescence as a predictor of adjustment in school. Contemporary Educational Psychology, 39(4), 400-388. http://dx.doi.org/10.1016/j.cedpsych.2014.09.003

Raufelder, D., Hoferichter, F., Ringeisen, T., Regner, N., \& Jacke, C. (2015). The Perceived Role of Parental Support and Pressure in the Interplay of Test Anxiety and School Engagement among Adolescents: Evidence for Gender-Specific Relations. Journal of Child and Family studies, 1-15. http://dx.doi.org/10.1007/s10826-015-0182-y

Reeve, J., Jane, H., Carrell, D., Jean, S., \& Barch, J. (2004). Enhancing students engagement by increasing

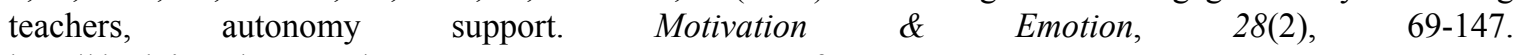
http://dx.doi.org/10.1023/B:MOEM.0000032312.95499.6f

Reeve, J., \& Tseng, C. M. (2011). Agency as a fourth aspect of students' engagement during learning activities. Contemporary Educational Psychology, 36(4), 257-267. http://dx.doi.org/10.1016/j.cedpsych.2011.05.002

Sarason, I. G. (1984). Stress, anxiety and cognitive interference: Reactions to tests. Personality and Social Psychology, 46, 929-938. http://dx.doi.org/10.1037/0022-3514.46.4.929

Sarason, I. G. (1988). Anxiety, self-preoccupation and attention. Anxiety Research, 1, 3-8. http://dx.doi.org/10.1080/10615808808248215

Shernoff, D. J., \& Hoogstra, L. (2001). Continuing motivation beyoun the highschool classroom. New dirrections in child and Adolescent Development, 93, 73-87. http://dx.doi.org/10.1002/cd.26

Shernoff, D. J. (2013). Optimal learning environments to promote student engagement. New York: Springer. http://dx.doi.org/10.1007/978-1-4614-7089-2

Skinner, E. A. (1995). Perceived control, motivation, and coping. Newbury Park, CA: Sage. http://dx.doi.org/10.4135/9781483327198

Spielberger, C. D., \& Vagg, P. R. (1995). Test Anxiety: Theory, Assessment and Treatment. Washington, DC: Taylor \& Francis Publishing.

Talley, A. E., Kocum, L., Schlegel, R. J., Molix, L., \& Bettencourt, A. (2012). Social roles, basic need satisfaction, and psychological health: The central role of competence. Personality and Social Psychology Bulletin, 38(2), 155-173. http://dx.doi.org/10.1177/0146167211432762

Veiga, F. H. (2016). Assessing Student Engagement in School: Development and Validation of a Four-dimensional Scale. Procedia-Social and Behavioral Sciences, 217, 819-813. http://dx.doi.org/10.1016/j.sbspro.2016.02.153

Zimmer-Gembeck, M. J., \& Collins, W. A. (2003). Autonomy development during adolescence. In G. R. Adams, \& M. Berzonsky (Eds.), Blackwell Handbook of Adolescence (pp. 175-204). Oxford: Blackwell Publishers.

\section{Copyrights}

Copyright for this article is retained by the author(s), with first publication rights granted to the journal.

This is an open-access article distributed under the terms and conditions of the Creative Commons Attribution license (http://creativecommons.org/licenses/by/4.0/). 